\title{
Feeding behavior and nutritional aspects of children using an adapted version of Children's Eating Behavior Questionnaire
}

\author{
Gabriela de Paula Silva (IC), Emanuella Meira Paschoaleto (IC), Maria Beatriz D. Gavião (PQ)
}

\section{Abstract}

This research aims to evaluate the feeding behavior in pre-school children. In this first part, it was performed the adaptation of the Portuguese version (Portugal) of the Children's Eating Behavior Questionnaire (CEBQ) for Portuguese Brazilian language, which was applied in mothers of 15 children aged three to six years. It was added an option "I did not understand" in each question to verify the comprehensiveness of at least $85 \%$ of the questionnaire. All questions were answered properly and the respective scores were in line with the original version. This version of the CEBQ can be considered adequate for Brazilian parents.

Key words: Child, feeding, nutrition.

\section{Introduction}

The food preference, the diet and nutrition can be affected by oral conditions; the difficulty on chewing due to poor oral health is the most probably factor that influences the feeding. The negative consequences for children with nutritional problems can affect the psycho-social development and well-being. The aim of this research is to evaluate the feeding behavior in pre-school children and to verify the possible associations with oral and nutritional conditions. In the first part, which is the focus of this presentation, it was performed the adaptation of the Portuguese version (Portugal) of Children's Eating Behavior Questionnaire (CEBQ) for Portuguese Brazilian language. This questionnaire contained the most comprehensive coverage of different eating styles, and has been shown to be valid and reliable ${ }^{1}$. It is designed to be completed by parents in relation to their child's habitual eating behaviors, assessing eight aspects of children's appetite (Chart 1).

\section{Results and Discussion}

The Portuguese version of the $C E B Q^{2}$ was applied in mothers of 15 children, three boys and 12 girls, aged three to six years, after some adaptations made by two Brazilian native people. This is a thirty-five-item parent-rated questionnaire using fivepoint Likert frequency scales $(1=$ never to $5=$ =always). It was added an option "I did not understand" in each question to verify the comprehensiveness of at least $85 \%$ of the questionnaire. Children's heights and weights were reported by the mothers and the BMI and the $z$-scores were calculated ${ }^{3}$. The mean BMI was $16 \pm 3.6$ and the individual values showed that five children were underweight, four normal weight, one overweight and five obese, the last ones above 4 years old. All questions were answered properly and the respective scores were in line with the original version (Chart 1).

Chart 1. Descriptive data for $C E B Q$ sub-scales

\begin{tabular}{|l|l|l|l|}
\hline $\mathrm{n}=15$ & Means $\pm S D$ & \multicolumn{1}{|c|}{ Median (ID) } & \multicolumn{1}{c|}{ Range } \\
\hline $\mathrm{EF}$ & $4.18 \pm 0.72$ & $4(1.00)$ & $3-5$ \\
\hline $\mathrm{FR}$ & $3.30 \pm 0.85$ & $3.25(1.38)$ & $2-4.75$ \\
\hline $\mathrm{SR}$ & $2.90 \pm 0.61$ & $3(0.75)$ & $1.5-3.75$ \\
\hline $\mathrm{SE}$ & $3.19 \pm 0.84$ & $3.25(1.4)$ & $2-4.75$ \\
\hline FF & $4.27 \pm 0.86$ & $4.25(0.63)$ & $1.75-5.25$ \\
\hline EOE & $1.65 \pm 0.72$ & $1.67(1.00)$ & $0.75-3$ \\
\hline EUE & $2.06 \pm 0.91$ & $2(1.75)$ & $1-3.33$ \\
\hline DD & $2.48 \pm 1.08$ & $2.25(1.88)$ & $1-4$ \\
\hline
\end{tabular}

Enjoyment of food (EF); Food responsiveness (FR); Satiety responsiveness (SR); Slowness in eating (SE); Food fussiness (FF); Emotional over-eating (EOE); Emotional under-eating (EUE); Desire to drink (DD)

Previous studies ${ }^{1,2}$ showed that this tool is valuable for identifying specific eating styles that may be implicated in the development of obesity. In this way, it will be used further in a larger sample to verify if the oral conditions can influence the feeding behavior and nutritional aspects in pre-school children.

\section{Conclusions}

The Portuguese Brazilian adaptation of the CEBQ can be considered adequate to apply in Brazilian parents to identify eating styles of their children.

\section{Acknowledgement}

We are grateful to PIBIC/SAE/UNICAMP for the scholarship for the first author.

\footnotetext{
${ }^{1}$ Wardle, J.; Guthrie, C. A.; Sanderson, S.; Rapoport, L. J Child Psychol Psychiatry 2001, 42:963-970.

${ }^{2}$ Viana, V.; Sinde, S.; Saxton, J. C. Br J Nutr. 2008;100:445-50.

${ }^{3}$ Centers for Disease Control: Growth Charts (2000) http://www. cdc.gov/nccdphp/dnpa/growthcharts/resources/CDCGrowthChar ts5-2002.ppt. (acessed July 24, 2015).
} 